\title{
Communhão de facto entre conjuges italianos, sobre bens adquiridos no Brasil
}

O que nos propomos explanar pode ser assim enunciado, valendo-nos da ementa, que encima uma decisão do Ministro Laudo de Camargo (1):

"Italianos os conjuges, e casados na Italia, os bens adquiridos no Brasil, para onde vieram, sem nada possuir, passaram a ser communs, desde que juntos sempre viveram, e juntos trabalharam."

Convem desdobremos a especie em apreço em duas hypotheses: a) o casal de italianos, enriquecidos no Brasil pelo esforço commum de ambos os conjuges, tem filhos brasileiros; b) não tem filhos o referido casal de italianos.

(1) Decisões, p. 121. 
Dando solução ao problema, nas diversas vezes que elle se tem apresentado ao Egregio Tribunal de Justiça de São Paulo, delinearam-se alli, de modo distincto, duas correntes antagonicas, ás quaes chamaremos, a uma, liberalevolucionista, e a outra, radical-conservadora.

Para o verificar, é apenas percorrer os arestos do emerito Collegio, dos quaes citaremos alguns, a partir de 1922.

E' assim que, a 21 de fevereiro daquelle anno, dando provimento á Appellação 10.978, de Piracicaba, relator o Exmo. Sr. Ministro Soriano de Souza, e voto vencido o Exmo. Sr. Ministro Octaviáno Vieira, o Tribunal firmou aresto, dizendo que, num casal de italianos, não havendo communhão de bens, a menos que venha expressamente estipulada no contracto antenupcial, não poderá a mulher pretender a meação do marido, mesmo provado que os bens do casal foram adquiridos pelo esforço commum de ambos na constancia do matrimonio. R. T. 43, p. 371.

Já noutro aresto, pouco mais de um mez após, a 30 de março do mesmo anno, relator designado o Exmo. Sr. Ministro Julio de Faria, Aggravo 11.613, de Limeira, deixava claro que, embora não pactuada antenupcialmente a communhão de bens uteis, que os conjuges italianos viessem a adquirir durante o seu casamento, poderia ter existido uma communhão de facto, de vez que a acquisição de taes bens poderia provir do esforço commum, da economia conjugada de ambos os conjuges. R. T., 42, p. 36.

Fére-se o mesmo ponto de vista no accordam de 5 de novembro de 1923, relator o Exmo. Sr. Ministro Paula E Silva. Reza a respectiva ementa, textualmente:

"Muito embora os conjuges sejam italianos e se casem sob o regimen da lei nacional, sem contracto antenupcial, devem ser partilhados os bens por morte da mulher, se ficar provado que o casal nada possuia na epoca do casamento e o espolio foi adquirido pelo trabalho e economia de ambos." R. T., 48, p. 229. 
Ao inverso, consubstancia-se o ponto de vista radical-conservador, no Aggravo 13.113, de Jahú, accordam proferido a 15 de setembro de 1924, relator designado o Exmo. Sr. Ministro Martins de Menezes, vencido o Exmo. Sr. Ministro Julio de Faria: estabelece-se que, "sendo os conjuges italianos, casados na Italia sob o regimen da separação de bens, o marido não é obrigado a, por morte da mulher, dar bens a inventario, mesmo que, vindos ha muitos annos para o Brasil, tenham aqui constituido, pelo trabalho commum, o patrimonio de que o marido ficou de posse". R. T., 51, p. 437.

Tratava-se de um caso de italianos que, já muitos annos antes da vigencia do Codigo Civil, tinha emigrado de sua patria para o nosso paiz.

Sustentara, então, o Exmo. Sr. Ministro Julio de Faria que, em casos como aquelle; a justiça mandava se applicasse a lei que estatúe o regimen da communhão, dominante do paiz, sob cujo amparo os conjuges viveram, trabalharam, e accumularam economias. Não era justo que se attribuisse o patrimonio assim formado a um só delles. Demais, deve-se sempre, em conflicto de leis, applicar a nossa, deixando-se de julgar por ella somente quando o direito patrio mandar se obedeça ao direito estrangeiro.

Já diversamente, foi julgado, pouco depois, a 4 de novembro do mesmo anno, accordam proferido nos Embargos 12.177, desta Capital, relator o Exmo. Sr. Ministro PINTo DE Toledo. Consta da respectiva ementa que, embora os conjuges sejam italianos de origem, provado que o marido se naturalizou brasileiro, exerceu emprego publico no Brasil e aqui se alistou como eleitor, o regimen de bens que deve vigorar é o da communhão. Morrendo sem ascendentes o marido, a totalidade dos bens do casal deve ser adjudicada á viuva. R. T., 52, p. 419.

Afinal, em accordam recente, proferido a 14 de fevereiro de 1930, nos Embargos 9.573, da Capital, relator ainda o Exmo. Sr. Ministro Pinto de Toledo, foi decidido que os bens adquiridos após o casamento, por ambos os conjuges 
e com recursos provenientes do trabalho e da economia delles, devem ser partilhados, meio a meio, embora seja de separação o regimen a que estão sujeitos, por sua lei nacional. R. T., 73, p. 346.

Esses, e varios outros arestos anteriores, deixam assignalada, na sua discordancia, a controversia que vinha lavrando entre os notaveis Ministros do Egregio Tribunal de Justiça de São Paulo, quanto á solução da especie em exame, e servem, ademais, de evidenciar que um facto relevante impressionára, sempre, a corrente liberal evolucionista, fazendo-a avultar cada vez mais, até tornal-a, como agora está, definitivamente victoriosa. $E$ tal facto vem a ser o de que a applicação da lei italiana á especie em debate, que ella jamais previu, redundaria, como adeante se verá, na iniquidade clamorosa, de se negar, á mulher italiana, e aos seus herdeiros, o mais elementar principio de justiça.

Tres factos, por via de regra, se verificam nos casaes italianos, que vêm tentar a vida no Brasil: I) nenhum pacto antenupcial existe, por onde tenham convencionado a communhão dos bens uteis, que de futuro adquiram; II) vêm, ambos, completamente pobres, sem nada trazerem para aqui; III) aqui, pondo esforços em commum, realizam um patrimonio.

Tentaremos mostrar, dentro em pouco, que a lei italiana não previu o facto, hoje positivo, comesinho entre nós, de que casaes de immigrantes italianos, que transferem o seu domicilio á America, onde, ao chegarem, naida mais possuem além da energia formidavel dos seus braços, pudessem, cooperando em effectiva communhão de trabalho constante, accumular fortuna, não raro consideravel.

Estudemos, por agora, a primeira das duas hypotheses, sob as quaes a especie em questão pode apresentar-se. Eil-a: tem filhos brasileiros o casal de italianos, que emigrou pobre para o Brasil e aqui se enriqueceu. 
Temos, em nosso Codigo Civil, a solução precisa dessa hypothese.

Dever-se-á applicar o disposto na parte final do art. 14 de sua Introducção, pelo qual, quando o estrangeiro tiver deixado filhos brasileiros, ficam sujeitos á lei brasileira a sua successão legitima ou testamentaria, a ordem da vocação hereditaria, os direitos dos herdeiros, e a validade das disposições do testamento.

O mesmo se dará, em se tratando de estrangeiro casado com brasileira. Aspecto do problema, porém, que nesta explanação não nos interessa.

Consoante o citado dispositivo, do art. 14 da Introducção ao Codigo Civil patrio, a existencia de prole brasileira, oriunda de um casal de estrangeiros, constitue, por si só, no que respeita aos direitos da mulher, larga protecção, protecção tão ampla quanto a que a nossa lei assegura ás brasileiras casadas sob o regimen legal de bens do nosso direito.

Assim é, uma vez que, no caso, se deverá observar a lei do Brasil, por existirem filhos brasileiros, e porque, pela lei brasileira, é regra geral o regimen da communhão de bens entre os conjuges, em cuja sociedade o direito patrio reconhece e assegura á mulher a qualidade de meeira.

E já ahi deixa de se dar a iniquidade,-que fatalmente decorre da applicação incondicional da lei italiana a toda e qualquer das diversas hypotheses, sob as quaes possa vir a concreto a especie de que nos occupamos.

\section{III}

Mas a hypothese, onde a discussão mais intensa se tornou, e em volta da qual a controversia mais se apertara, é a de não ter filhos o casal de italianos, enriquecidos no Brasil pelo esforço commum de ambos os conjuges.

Aqui, a cornente radical-conservadora pareceu sentir-se inexpugnavel nos argumentos a que se amparava, para sustentar e decidir, como indicámos ha pouco, que, embora o 
patrimonio de um casal de italianos, extincto pela morte do varão, tenha sido, comprovadamente, accumulado pela cooperação de ambos os conjuges em esforço commum, á mulher não assiste direito á meação do espolio. Nenhum dineito lhe cabe, dada a ausencia de qualquer pacto antenupcial, convencionado entre ella e o marido, á comunhão dos bens que de futuro, na constancia de seu matrimonio, separada ou conjunctamente, adquirissem.

Pois, a despeito de tudo o que se nos possa increpar, em contraposição aos argumentos, que vamos expender a seguir, ficamo-nos convicto ao lado da corrente, hoje inteiramente victoriosa, a que, para bôa ordem na exposição, demos o nome de liberal evolucionista, que vem sendo representada, entre outros, pelos Exmos. Srs. Ministros Octaviano Vieira, Julio de Faria, laudo de Camargo, Affonso de Carvalho, Sylvio Portugal, Mario Masagão e Junqueira SobriNHo, tão brilhantemente, quanto, com brilho egual, vêm representando a corrente radical conservadora, ao lado de outros, os Exmos. Srs. Ministros Soriano de Souza, Martins de Menezes, Luiz Ayres e Costa e Silva.

Liminarmente injusto é o dispositivo de lei, que assegura a alguem a usurpação do alheio.

Estaria sem remedio, nessas condições, o preceito do art. 1.433 do Codigo Civil Italiano, si ao invés de o interpretarmos sob um angulo menos estreito e num sentido mais humano, conciliando-o com as necessidades dimanantes de factos imperiosos, lhe dessemos a interpretação restricta de um preceito inflexivel.

\section{IV}

O litteralismo absoluto das interpretações leva, não poucas vezes, á inutilização de muito dispositivo de lei.

E' da jurisprudencia a missão salutar de supprir as lacunas da lei, corrigindo-lhe as deficiencias, aparando-lhe as demasías. 
Porque demasias e deficiencias das leis, raro as pode presentir, ou prever, o legislador. Ao passo que o juiz não as presente, apenas: sente-as palpitantemente, como experimentador da lei, ao applical-a todos os dias.

$O$ trato diuturno dos casos variados, que se lhe offerecem, mostra-lhe as excellencias como as falhas do preceito legal.

Si o legislador a elabora, é o juiz quem vivifica a lei.

Incide nos limites das suas attribuições de jurisdicente amenizar as possiveis injustiças do preceito codificado, sem pre que, accorde com a moral e segundo a bôa razão, se mantenha dentro no ambito traçado pelos principios geraes de direito.

Sem consultar e attender ao que se contem nos preceitos dos codigos, surgem os factos numa perpetua renovação transformadora, modificando o scenario da vida juridica. $E$ as lacunas vão-se revelando nos textos da lei; e essas lacunas têm que ser providas; e incumbe ao juiz o dar-lhes provimento.

Não raras vezes, tangida por necessidades irremoviveis, a jurisprudencia precede ao reajustamento da lei, e antes que ella se modifique, corrige-lhe as iniquidades, inspirada pelo sentimento da justiça.

\section{V}

Voltando ao nosso objecto, estamos em firmemente crêr que, na hypothese, existe a comunhão de facto, de que fala Bevilaqua, e na magistratura paulista vem sendo proclamada como razão de decidir, entre outros, pelos Exmos. Srs. Ministros Octaviano Vieira, Paula e Silva, Julio de Faria, Laudo de Camargo, adalberto Garcia, Affonso de Carvalho, Mafio Masagão, Sylvio Portugal e Jungueira Sobrinho.

Essa communhão de facto, que, dizem alguns, o direito italiano repelle, em these, é uma realidade incontestavel, 
na hypothese: nasceu, prosperou, consolidou-se e desabrochou fructos no actual domicilio do casal italiano.

Si a lei da Italia não a pode regular, porque a desconhece, deve regulal-a, suppletivamente, a lei do paiz em que nasceu e onde positivamente existe.

A jurisprudencia, hoje definitivamente victoriosa, e adoptada pela corrente liberal evolucionista do Tribunal de Justiça de São Paulo, repara uma injustiça revoltante.

Justo é, pois, decidir que, italianos os conjuges, e casados na Italia, os bens adquiridos no Brasil, para onde vieram, sem nada possuir, passaram a ser communs, desde que sempre viveram juntos e juntos trabalharam.

Em verdade, o direito italiano ordena seja previamente pactuada pelos conjuges a communhão doṣ bens uteis, que elles, unida ou separadamente, adquiram na constancia do casamento.

Mas essa prescripção não impede, nem tem a fôrça de impedir que, na constancia da sociedade conjugal, uma communhão de bens, meramente de facto, se consolide entre os esposos domiciliados noutro paiz. Si nada convencionaram tempestivamente, mais do que isso fizeram na realidade, mais do que isso realizaram no correr dos annos, indo muito mais além na pratica: effectivaram, por factos concretos e indeleveis, a comunhão positiva dos bens que accumularam pela actividade commum.

A jurisprudencia victoriosa no Tribunal de Justiça de São Paulo, merecedora de todo o applauso, não transgride a lei italiana, que silencia a hypothese.

E essa lei, bem analysada, nada dispõe contrario ao que vimos sustentando.

Nem nossa orientação posterga a norma estatuida pelo art. $8 .^{\circ}$ da Introducção ao nosso Codigo Civil, porquanto, conforme nos parece, a lei italiana deverá ser applicada, sempre, mas sempre ás hypotheses que ella previu e expressamente refere. 
Sem nos escudarmos no art. 1.436 do Codigo Civil Italiano, onde quer-nos parecer se não encontra elemento que em verdade autorize applicar á communhão de facto, cimentada entre conjuges italianos no Brasil, as regras daquelle Codigo relativas á "Sociedade", o ponto de vista, que professamos, tem por base outros fundamentos.

Attentemos em que, segundo a lei italiana, não havendo sido previamente convencionada a communhão, cada conjuge será proprietario dos bens que adquirir na constancia do casamento.

Isso, comtudo, não equivale a dizer que serão exclusivos do marido, ou da mulher, os bens porventura adquiridos pelo trabalho commum de ambos.

$\mathrm{O}$ que isso significa, e quer dizer, é, sim, que a marido e mulher assistem direitos eguaes sobre os bens que accumularam, conjugando esforços para o mesmo fim.

Com sustentar o contrario, teremos que admittir, por consequencia irrecusavel, que a lei italiana autoriza o marido a usurpar á mulher a parte, que legitimamente lhe pertence, no producto do esforço commum; abroquella, contra o mais rudimentar espirito de justiça, o usurpador da coisa alheia, assegurando-lhe a impunidade; espesinha, de animo deliberado, o principio basilar de direito, que é dar a cada um o que é seu.

Para nos fixarmos, bem vivo, a iniquidade, a que esse modo de vêr poderá conduzir, permittimo-nos figurar um exemplo: A e B, marido e mulher, são italianos.

Casados na Italia, sem nada possuirem, logo após emigram de lá para aqui; a principio, e como é regra geral, colonos de uma fazenda de café, adquirem, trabalhando juntos, o seu primeiro pé-de-meia. Esse pé-de-meia permitte ao marido a compra de uma carroça, com que passa a trajalhar na cidade, e ainda deixa modesta sobra, mediante a qual a mulher arrenda, nos arrabaldes, pequenina chacara, onde o casal entra a residir. 
Italiana, e sem filhos, a mulher, incansavel no trabalho de todos os dias, applica-se ao plantío de hortaliças, e pelas manhãs, quando o marido vem para a cidade, entregar-se ao trabalho de sua profissão de carroceiro, vem igualmente a mulher empurrando a sua carrocinha de verdura, e percorre as ruas, vendendo-as.

Decorrido algum tempo, pela tenacidade do esforço commum, e, economisando de commum accôrdo, o casal logra adquirir um sitio; e incansavel no trabalho, continuando marido e mulher a peleja da vida, chegam um dia a ser senhores e possuidores de uma grande propriedade agricola, iesultado final dos esforços mutuos de annos a fio, visando a realização do patrimonio, que agora avulta á admiração de todos.

Mas vem acontecer que o marido fallece pouco depois, ficando, do extincto casal, um consideravel acêrvo de bens.

$\mathrm{E}$ agora, eis que, aberta a successão do de cujus, vão ser submettidos a inventario os bens constantes do espolio; e então teremos, ao applicar a lei italiana a esse caso, de uma positiva communhão de facto, - que ella não previu $e$ por isso não regula, - teremos, então, chegado ao seguinte absurdo: porque não foi pactuada a communhão de bens uteis, que os conjuges porventura adquirissem na constancia do seu casamento, surgem os herdeiros do marido e, á sombra da lei italiana, reclamam, e levantam a maxima parte do patrimonio constante do espolio, praticada, dess'arte, com todos os sacramentos judiciaes, a calamidade sem nome, a dolorosa ironia, de se arrebatar ás mãos da viuva, sem remedio juridico possivel, o que inquestionavelmente lhe pertence no patrimonio-realização dos esforços communs de ambos os conjuges, na labuta diaria de outróra, em a qual conjuntamente se empenharam.

Não; não se pode conceber que tamanha injustiça encontre abrigo dentro num preceito do Codigo Civil Italiano, formoso monumento juridico do mundo contemporaneo.

Preferimos interpretal-o, reconhecendo que elle não previu e por isso não regula, a hypothese de que conju- 
ges italianos, casados na Italia sob o regimen da separação de bens, - sem nada possuirem quando se casaram, sem haverem estipulado em tempo habil a communhão dos bens uteis que um dia, porventura adquirissem, -- pudessem e viessem, muitos annos depois de domiciliados noutro paiz, nelle realizar uma innegavel communhão de facto, uma communhão de facto positiva, respeito aos bens constantes do patrimonio, que o esforço reciproco de ambos passo a passo amealhou.

De vez que essa hypothese, que realmente existe e se repete todos os dias no Brasil, não pode ter solução justa dentro nos termos da lei italiana, que a não regula, antes a desconhece e sobre ella silencia; de vez que, por assim dizer, constitue um caso omisso da lei italiana a inexistencia, nella, de preceito que se possa invocar para esse caso de uma communhão de facto entre os conjuges italianos domiciliados no Brasil; e de vez, ainda, que o nosso systema de Direito Internacional Privado prescreve que, em nenhum caso, o juiz poderá deixar de julgar, applicando-se, aos casos omissos, os principios geraes de direito, certo estará o juiz, resolvendo a especie de accôrdo com a lei brasileira, que é, não só a lex-fori, como tambem a lei do domicilio do casal, lei a que se outorga a funcção suppletiva, nas hypotheses em que seja impossivel á lei nacional da pessôa dar solução.

\section{VII}

E quando dizemos, que, nesse caso, antes de tudo nos deve inspirar o sentimento da justiça, é precisamente para lembrar que o "a cada um o que é seu" é um principio fundamental de direito, que não conhece os limites de imperio das soberanias territoriaes. E' um principio, cuja supremacia deve ser indiscutivel, onde quer que seja, do mundo civilizado.

Nenhum Codigo se lhe pode oppôr; nem a elle poderia contravir o nosso systema de Direito Internacional Privado. 
Não é possivel pôrmos em duvida que ao juiz e tribunaes brasileiros peza applicar a lei italiana: $a$ ) quando se tratar da successão de italiano que tenha pactuado, com o seu conjuge, a communhão dos bens uteis, adquiridos por um delles separadamente, ou por ambos em conjunto; $b$ ) quando o espolio se compuzer somente de bens particulares, de propriedade exclusiva de cada um; c) ou quando, ainda, tendo ambos lutado, numa vida de trabalho continuo, ficar, todavia, sufficientemente provado que entre elles se não estabeleceu nenhuma communhão de facto, quanto aos bens do patrimonio que por esforços communs consolidaram no Brasil.

Embora a lei italiana desconheça, e por isso, não a regule, a communhão de facto, entre conjuges italianos, se verifica a cada passo, e casos della se nos deparam quotidianamente, por todo o vasto territorio do Estado de São Paulo. E' uma expressão de vinculo juridico, dessas que muita vez, e sem formalidades, surgem por toda parte, e as contigencias da vida, no tempo e no espaço, multiplicam.

A base necessaria, para se dar solução aos problemas do direito, por mais complicados que sejam e se nos apresentem, é submettel-os, sempre, ao mesmo denominador commum de todos os problemas juridicos, que é a justiça, e assim reduzil-os á sua expressão mais simples, que é o "suum cuique tribuere".

\section{VIII}

Não foi outro o intuito destas linhas, senão o de patentear aqui nosso applauso á these, que, sustentada pela corrente liberal evolucionista, se tornou definitivamente victoriosa no Tribunal de Justiça deste Estado, e que reconhece o direito de meação ao conjuge superstite de um extincto casal de italianos, cujo patrimonio foi conquistado no Brasil pelo trabalho mutuo de ambos, collaborando ininterruptamente na concretização do mesmo sonho. 
Como remate de ouro ás ligeiras considerações, por nós adduzidas, e em resposta á allegação, que é de costume fazer-se quanto á irrevogabilidade do regimen de bens no casamento, é de todo em todo proveitoso terem-se sempre em mente as seguintes palavras do illustre Ministro Affonso de Carvalho, em dois dos seus varios e substanciosos votos, attinentes á materia: "Quanto a esta irrevogabilidade, eu estou de accôrdo, uma vez que se trate de bens existentes ao tempo do matrimonio. Mas, se os conjuges não tinham bens de qualquer especie, quando se casaram; se esses bens se adquiriram na constancia do matrimonio, por esforço de ambos, marido e mulher, então a questão muda de face, e não é possivel sustentar aquella these de modo absoluto. Dadas as circumstancias, a lei que regula os direitos successorios ha de ser a nossa". R. T., 74, p. 344. "... a lei italilana, quando adopta para os conjuges o regimen da separação de bens, não declara que os bens supervenientes, devidos ao esforço commum do casal, devam sempre pertencer exclusivamente ao marido. Não seria isso regimen de separação de bens, mas o de usurpação de bens. Regimen de separação de bens não quer dizer, evidentemente, regimen no qual não se admitta communicação de bens, por meio de sociedade de facto, para que tudo que o casal e os filhos adquirirem, pelo esforço conjunto, fique de direito pertencendo exclusivamente ao chefe da familia". R. T., 71, p. 450.

\section{IX}

O ponto de vista, actualmente victorioso no Egregio Tribunal de Justiça de São Paulo (2), respeito á hypothese em apreço, nada mais significa que a reparação de uma iniquidade, pela applicação de um elementar principio de justiça.

S. Paulo, 23-XII-931.

\section{F. PINTO PEREIRA.}

(2) Revista dos Tribunaes: 24/324 - 24/325 - 42/36 $48 / 229-48 / 249-73 / 346-74 / 342-75 / 487-78 / 481-79 / 176$. 